\title{
Article
}

\section{Clinical academic research internships for nurses, midwives and allied health professionals: a qualitative evaluation}

Miller, Colette, Cook, Julie, Gibson, Josephine, Watkins, Caroline Leigh and Jones, Stephanie

Available at http://clok.uclan.ac.uk/32051/

Miller, Colette ORCID: 0000-0003-0620-6029, Cook, Julie ORCID: 0000-00026391-5430, Gibson, Josephine ORCID: 0000-0002-3051-1237, Watkins, Caroline Leigh ORCID: 0000-0002-9403-3772 and Jones, Stephanie ORCID: 0000-0001-9149-8606 (2021) Clinical academic research internships for nurses, midwives and allied health professionals: a qualitative evaluation. Nurse Researcher, 29 (1). ISSN 1351-5578

It is advisable to refer to the publisher's version if you intend to cite from the work. http://dx.doi.org/10.7748/nr.2020.e1724

For more information about UCLan's research in this area go to

http://www.uclan.ac.uk/researchgroups/ and search for <name of research Group>.

For information about Research generally at UCLan please go to http://www.uclan.ac.uk/research/

All outputs in CLoK are protected by Intellectual Property Rights law, including Copyright law. Copyright, IPR and Moral Rights for the works on this site are retained by the individual authors and/or other copyright owners. Terms and conditions for use of this material are defined in the policies page. 
Clinical academic research internships for nurses, midwives and allied health professionals:

A qualitative evaluation.

\begin{abstract}
$\underline{\text { ABSTRACT }}$
Background: Nurses, midwives and allied health professionals are integral to research, yet rarely engage simultaneously in research and clinical practice. Clinical academic internships offer a route to access academic research training. This study aimed to elucidate facilitators and barriers to participation and engagement, and suggest improvements for future programmes. Method: The experiences of 10 health professional research interns were explored, using a method based on a synthesis between grounded theory and content analysis. Findings: Four categories emerged: 1) integrating clinical and research aspirations; 2) Support - or lack of it; 3) The hidden curriculum; 4) The legacy effect. Within these categories, respondents identified a variety of facilitators and barriers to engagement, including unforeseen challenges. Conclusion: Formal support is necessary but not sufficient to foster engagement and maximise benefits. Participation must be supported by colleagues and enabled by institutional structures. The potential impact of internships on engagement with research is considerable but requires collaboration between all stakeholders. Implications for Practice: Deeper institutional engagement is needed so that internship opportunities are fully supported by all colleagues and practically enabled by institutional structures. Future schemes should attempt to promote opportunities to collaborate via group projects to reduce researcher isolation.
\end{abstract}

Keywords: Clinical Academic; Research; Education; Health Personnel; Interdisciplinary Education; Qualitative Research 
The development of a research culture in nursing, midwifery and allied health professions (NMAHPs) is essential for evidence-based healthcare. Historically, clinically active NMAHPs have rarely led or collaborated in research that contributes to their discipline's evidence base (Health Education England, 2015; Gibson, 2019). Their involvement in research often entails promoting the implementation of evidence-based practice, or co-ordinating and delivering research projects led by medically qualified clinical academics (Whitehouse, 2018). There is increasing international evidence that research-active practitioners enable healthcare organisations to provide better quality care and improved patient outcomes (Krzyzanowska et al., 2011; Ozdemir et al., 2015, Van Oostveen et al., 2017, Windsor et al., 2015; Windsor et al., 2017).

Clinical academics 'work in health and social care as clinicians to improve, maintain, or recover health while in parallel researching new ways of delivering better outcomes for the patients.' (NHS NIHR, 2016 p11). Challenges to career pathways for NMAHPs identified in the UK, as well as Australia and New Zealand (Windsor et al., 2015; Windsor et al., 2017) include demands on both time and expertise, with practitioners having to develop and maintain professional credibility in 'multiple arenas' (Logan, Gallimore, \& Jordan, 2016). Culture, lack of infrastructure and leadership are important barriers (Van Oostveen et al., 2017). Many NMAHPs embark on doctoral level study only after achievement of senior clinical posts (Trusson et al, 2019). This is echoed by the World Health Organisation's global nursing strategy which discusses competence in 'evidence generation' only for nursing leaders (WHO, 2016).

Several initiatives in the UK sought to develop clinical academic career pathways, such as the development of joint lecturer-practitioner appointments between Higher Education Institutions (HEI) and health providers. However, these often focused on combining pre-registration level teaching with clinical practice, with little engagement in conducting research (Williamson, 2004). The NHS introduced NMAHP consultant roles in 2000 (Department of Health, 1999), to enable practitioners to 
combine $50 \%$ clinical practice with teaching, research and management activities. Several evaluations of these roles suggest that many NMAHP consultants undertake little or no primary research, although they do engage in activities such as raising research awareness and conducting audits (Humphreys et al., 2007; Avery and Butler 2008; Kennedy et al., 2011). These senior posts do not in themselves provide an obvious stepping-stone for aspiring early or mid-career clinical academics. Furthermore, an evaluation of tensions in research collaboration between HEls and NHS trusts found a mismatch between organisational commitment and the support received by aspiring NMAHP clinical academics. Immediate clinical work was often prioritised, whilst academic activity was at times referred to by NHS managers as 'research rubbish'; some respondents felt that only large medically-led research studies were supported (Springett et al., 2014).

In 2012, the UK National Institute for Health Research (NIHR) launched an integrated clinical academic pathway for NMAHPs with a competitive funding programme covering release from clinical practice (Department of Health, 2012). The first stage is for early career NMAHPs to participate in a clinical academic internship (Westwood et al., 2018). One programme, delivered by a team of experienced NMAHP health researchers from a HEl in the North of England, enables NMAHPs to take their first steps in developing a research career alongside their substantive clinical post. All healthcare staff, regardless of previous educational attainment, were eligible to apply for the opportunity. This inclusive approach ensured that no staff group was excluded. Individual ability was assessed through a rigorous application and interview process, and subsequent support was tailored to individual learning needs. Interns were released from clinical practice for typically one day per week for 12 months to undertake a small clinical research project on a topic agreed with their managers. This approach is unusual; such internships typically focus on the development of research skills, viewing independent research as something for later in the pathway, e.g. PhD. The taught aspect of the programme consisted of ten training days delivered by the HEI, detailed in Table 1. Individual support was provided by clinical line managers, the employing organisation's research and development department, and an academic supervisor from the HEI. 

far been little exploration of the experiences of those involved (Hiley and Swift, 2016; Kane et al., 2016).

To explore NMAHPS' experiences of undertaking a clinical academic internship programme and to identify facilitators and barriers to participants' engagement.

\section{METHODS}

Participants and Setting

Purposive sampling from one cohort of an internship programme hosted at a $\mathrm{HEl}$ in the North of England, UK. Data collection took place August-September 2014.

\section{$\underline{\text { Recruitment }}$}

All 12 interns were verbally informed about the evaluation at a training day, with the opportunity to ask questions. An email invitation and participant information sheet were sent by the lead researcher. After two weeks, a second email was sent and those who agreed to participate were invited to interview.

\section{Data Collection}

Face-to-face interviews were conducted shortly before the end of the programme, at a time

91 and place chosen by the participant. The semi-structured interview guide, Table 2, mirrored the

92 chronology of the programme. Participants were asked to reflect on the programme's impact on their

93 day-to-day practice, and future educational and career aspirations. Interviews were audio-recorded

94 and transcribed verbatim (authors 1 and 2) (Creswell and Creswell, 2018). 

analysis, was followed. Authors 1 and 2 independently open-coded the transcripts, facilitated by NVivo (V10) software. Disagreements in coding and categorising were resolved via third party adjudication (author 4). Emerging themes were identified and grouped under four higher-order headings.

\section{Ethical considerations.}

Ethical approval was granted by the host HEI STEMH ethics committee (Ref No: 231). To minimise the power differential between researcher and participant (Holloway and Wheeler, 2010) the evaluation was led by researchers not directly involved with the programme. Interns were under no obligation to participate, and two chose not to. To prevent identification of participants, personal information such as gender was not recorded, and contextual information such as job title or work setting is not reported. desire to improve patient care.

Some interns were influenced by previous exposure to research during educational

\section{FINDINGS}

Ten interns participated. Interviews lasted 14 - 73 minutes. Professions represented were nurse $(n=3)$, occupational therapist $(n=3)$, physiotherapist $(n=2)$, midwife $(n=1)$, and public health specialist $(n=1)$.

Integrating clinical and research aspirations

Participants' motivations to better understand evidence-based practice were influenced by a "If we can make improvements for the patients... at the end of the day it's making a difference." (Participant 10) experiences, or involvement in clinical research delivery. 

"I got involved in the $[X]$ project... promoting it on the ward and identifying potential participants... and just thought, I want to get more involved with research." (Participant 6)

Interns were motivated to explore this career direction without the time commitments or personal and professional life changes that might be incurred by undertaking Master's- or Doctorallevel study. The programme appeared to address an unmet need for short-term development opportunities.

"It can be quite daunting can't it, to research and things so it [the internship] looked... a way that I could... check it out without actually jumping in too deep." (Participant 3)

\section{Support - or lack of it}

Interns had a variety of clinical and educational backgrounds, and felt this diversity was acknowledged in the teaching approach.

"They [taught sessions] were aimed at somebody who'd never done research before. They didn't go into it too academically, which is great because that would have put everybody off...it was kind of a working knowledge of what to do next which I thought was fine - it was exactly the right approach." (Participant 9)

They placed particular value on the supportive nature of the programme's academic facilitation.

"So, it's been really, really supportive. I feel really nurtured actually, by all aspects..." (Participant 7).

Likewise, support from managers facilitated interns' engagement and increased support from the wider team. 
"I've received a lot of encouragement from [the service manager] and within my team. Within [service] staff-wise... who I work with directly, they've been brilliant." (Participant 8)

Some interns reported that most of their colleagues were supportive.

service delivery. else, which it wasn't. Yeah, she talked about it. And she's been openly quite negative about it." (Participant 6)

"...when I went into the MDT [multidisciplinary team] meeting I said to the consultant, 'I won't be in the meeting next week, I'm doing a research internship, '... He was a bit like, 'Oh right, well...we're short staffed, why are they letting you do that?'”' (Participant 8) 
formal support from their direct manager and their research and development department, yet the existing hierarchical, medically-led culture of clinical academic research was often unsupportive.

"One of the other consultants said he's never heard anything so ridiculous (laughs nervously) - as a [X] doing research." (Participant 8)

The hidden curriculum

There were many benefits from adopting a shared inter-professional philosophy for the programme. These were most apparent in the 'hidden curriculum', as interns suggested that the group sessions facilitated informal learning which was not part of the educational objectives.

"But support and... just having a chat at lunchtime, 'What do you think about, this/that?', you know, and thinking, 'Alright - different perspective'...you're not on your own." (Participant 10)

Despite their different areas of practice, interns found they shared vocational aspirations and challenges to developing as clinical academics, which bridged the inter-professional barriers sometimes present in clinical practice.

"You're drawing on lots of backgrounds and resources...I've enjoyed listening to other people and thinking, there's such a wealth of backgrounds and...people out there that want to improve the services that they're working in." (Participant 3)

Attending regular sessions as a cohort enabled the interns to form close and supportive connections, creating a shared experience. This helped to overcome some of the professional isolation which is sometimes experienced when undertaking career development opportunities.

"...one of the benefits of doing it (research) through the internship programme, is at times when you felt quite isolated around what you're dealing with or 
managing, is that when the interns come together, you realise you're not having a unique experience." (Participant 2)

188

\section{The legacy effect}

The interns developed confidence to make immediate changes to their professional practice.

Several of them identified ways they had implemented their learning in the clinical setting.

"...because I have become more interested, I am reading more literature about different things, so trying to put that into practice and say, 'Well actually we're doing this wrong, so let's...'. I'm feeling better about myself, that I'm performing better in my job." (Participant 10)

"...I've learned more about what I was doing by doing the search...and there's quite a few times when I was scanning and screening on title, and 'I don't need for that, but that's gonna be really handy for the other thing I'm doing'." (Participant 9)

Others were aware of the benefits of their new skills to their multi-disciplinary team. "...I can be a point of call within the service now, if people are sort of planning a project or planning some kind of evaluation or consultation, for them to speak to me first." (Participant 2)

Those who had previously been hesitant to consider further research or study felt empowered to progress.

"It's given me an energy to think, 'Well, it doesn't need to end here'... this isn't some kind of mystical thing (laughs) that only the chosen few can get into." (Participant 3) 
"And the idea that now I could do a PhD...that...suddenly that seems so much more...accessible than it was. The idea that...that was just what other people did. (whispers) That maybe I could do that. That would be exciting." (Participant 6)

\section{DISCUSSION}

Clinical academics are integral to the development, implementation and evaluation of evidence-based healthcare. The variability in clinical academic training, and the challenges of recruiting and retaining clinical academics, have previously been highlighted (Windsor et al., 2015).

Several motivating factors appeared to influence interns' engagement, notably previous exposure to research and the desire to improve patient care. This reflects the assumptions of policy, and the importance of developing clinical academic roles to ensure that research is designed and conducted in response to clinical issues, and findings are translated into clinical practice (Morris et al., 2011; Krzyzanowska et al., 2011; NIHR, 2016). In a recent realist synthesis, Cooke et al. (2018) identified 'making a difference' as a symbolic mechanism which not only effects research capacity development, but also signals its importance.

Interns felt their diverse educational backgrounds were acknowledged in the taught programme. Feelings of isolation in the clinical setting during the internship were common, but the group provided much-needed support, and opportunities to learn from one another across professions. Haralambos and Holborn (2008) describe this as the hidden curriculum; 'the unintended, and often unacknowledged, learning that occurs during a programme of study'. There have been several calls for greater cross-disciplinary collaboration in professional development opportunities (Pickstone et al., 2008; Roddam et al., 2019), yet a recent review of studies from 7 countries found that uni-professional education is common (Jones et al., 2018). It could be argued that internship programmes that reflect the complex multi-disciplinary ethos of patient care might be more effective 
in improving outcomes than initiatives that focus on the delivery of profession-specific training. This approach has been described as 'Mode 2' knowledge production, or 'co-producing knowledge'; the result of non-hierarchical, multi-professional groupings with heterogenous skills and experiences, and has been identified as a mechanism for effective research capacity development (Cooke et al., 2018).

Findings also shed light on participants' internal motivations and barriers. Notably, participants did not explicitly identify career progression as a motivation. A strong element of the interns' accounts was hesitancy about taking initial steps into research. The internship offered an accessible opportunity to gauge their interest and aptitude without the risks associated with career change or commitment to long-term study. This finding is of interest against the policy background that assumes movement of clinicians into research demonstrates leadership progression (WHO, 2016; Trusson et al., 2019).

The UK Department of Health strategy for nurse consultants recognised the need 'to enable experienced nurses to remain in clinical practice rather than move into management' (Kennedy et al., 2011 p2). However, lack of understanding of, and engagement in research by those who do pursue management career pathways may lead to a lack of vision, weak leadership and disempowerment of aspiring clinical academics. Van Oostveen et al. identified 'the absence of supporting structures for nurses who combine clinical and academic work' $(2017, \mathrm{p} 4974)$ as a deficiency in facilitating clinical academic careers for nurses in particular.

Although most participants found their peers and managers were supportive, there were some striking negative, hostile and bullying attitudes. This is out of step with the espoused values of the NHS and its commitment to research, but echoes tensions described by Springett et al. (2014). Critical attitudes towards clinical academic nurses were also reported from the Netherlands (Van Oostveen et al. 2017).

Clinical academic internship programmes in the UK adopt heterogenous approaches to design and delivery, yet comparable themes emerge when they are evaluated. Hiley and Swift's findings 
257 (2016), also included the participants' general motivations to find out more about research, and the importance of good supervision during the programme. A further evaluation reported interviews with seven senior clinicians on a clinical academic career programme. It concluded that barriers are generated by mainly institutional concepts; 'managers must provide systems and strategies to support the leadership and research opportunities' (Kane et al., 2016).

The findings from our study, that prospective interns are not always motivated by career development, and experience a range of challenges from their colleagues and senior staff, offer a richer understanding of both the internal and external barriers to NMAHPs accessing clinical academic routes. The design and delivery of future programmes may be improved by recognising that not all participants may yet have committed to research as a career pathway.

We suggest that such bespoke training programmes can be accessible and empowering, raising the aspirations of staff from non-traditional research roles, and contributing to widening participation and enhancing diversity (The Association of UK University Hospitals, 2016 p21). Westwood et al. (2018) recommend an incremental approach to academic and clinical leadership, and describe key features for developing clinical academic capacity and capability. Further research is needed to explore the longer-term outcomes of such programmes, and how these may differ internationally.

\section{Limitations}

This evaluation was based on a small cohort, employed by healthcare organisations in the North of England, who completed one internship programme. The results may not be representative of other programmes and/or cohorts either in the UK or elsewhere. The evaluation included only the interns, and the impact on their colleagues, managers, and institutions is unknown. Interviews were undertaken within three months of the conclusion of the programme, and do not capture long-term impact. 
The findings from this study resonate with similar approaches in international settings.

284 Formal support from the interns' manager and organisation is necessary, but not itself sufficient to maximise the benefits to individuals, organisations and patient care. Deeper institutional engagement is needed so that the opportunity is fully supported by all colleagues and enabled by institutional structures.

There appear to be profound benefits from intern-intern engagement. The isolation that researchers feel, perhaps especially as novices, can be ameliorated by this type of collaborative programme. Future programmes could take this further, for example by supporting small teams of practitioners to collaborate on co-designed projects. This would more closely mirror the reality of research in health care, which is rarely the work of one person but entails collaboration within and between healthcare organisations. 
Association of UK University Hospitals (AUKUH) (2016). Transforming healthcare through clinical academic roles in nursing, midwifery and allied health professions: A practical resource for healthcare provider organisations. Clinical Academic Roles Development Group. Retrieved from https://www.medschools.ac.uk/media/2325/aukuh-transforming-healthcare.pdf.

Avery, L., \& Butler, J. (2008). An evaluation of the role of diabetes nurse consultants in the UK. J Diabetes Nurs. 12(2), 58-63. doi: 10.1080/13625180701617621.

Burnard, P. (1991). A method of analysing interview transcripts in qualitative research. Nurse Educ Today. 11, 461-466.

Cooke, J., Gardois, P. \& Booth, A. (2018) Uncovering the mechanisms of research capacity development in health and social care: a realist synthesis. Health Res Policy Syst. 16:93.

Creswell, J., \& Creswell, J. (2018). Research Design: Qualitative, Quantitative, and Mixed Methods Approaches. (5 ${ }^{\text {th }}$ Ed.). California. Sage.

Department of Health (1999). Making a Difference: Strengthening the Nursing, Midwifery and Health Visiting Contribution to Health and Healthcare. Department of Health. London.

Department of Health (2012). ICA HEE/NIHR Integrated Clinical Academic Programme for nonmedical healthcare professions. Retrieved from https://www.nihr.ac.uk/funding-andsupport/funding-for-training-and-career-development/training-programmes/nihr-hee-icaprogramme/

Gibson, J. M. (2019). Shouldn't we all be clinical academics?. J Adv Nurs. 75, 1817-1818. doi:10.1111/jan.14026

Haralambo, M., \& Holborn, M. (2008). Sociology: Themes and Perspectives. ( $7^{\text {th }}$ Ed.). London. Harper Collins. 
Health Education England. (2015). Raising the bar - Shape of caring: A review of the future education and training of registered nurses and care assistants (The Willis Report). Leeds: Health Education England.

Hiley, J., \& Swift, A.A. (2016). Collaborative approach to develop clinical academic careers for scientists, nurses, allied health professionals and pharmacists: Annual R\&D Forum Conference 2016. Retrieved from http://www.annualrdforum.org.uk/wpcontent/uploads/2016/02/CollaborativeApproach.pdf.

Holloway, I., \& Wheeler, S. (2010) Qualitative Research in Nursing and Healthcare. Wessex, UK: Blackwell.

Humphreys, A., Johnson, S., Richardson, J., et al. (2007). A systematic review and meta-synthesis: evaluating the effectiveness of nurse, midwife/allied health professional consultants. J Clin Nurs. 16, 1792-1808. doi:10.1111/j.1365-2702.2007.01757.x

Jones, S., Gibson, J.M.E., Miller, C., et al. (2018). The impact of educational interventions for nurses and other health care staff on stroke patient care: an integrative review. Nurse Educ Today. 61, 249-257. http://dx.doi.org/10.1016/j.nedt.2017.11.024

Kane, R., McGonagle, I., Jackson, et al. (2016). Delivery of a clinical academic career programme: a collaborative approach - An example from England. Presented at International Scientific Conference for Research and Education in Nursing, Maribor, Slovenia. June $16^{\text {th }} 2016$. ISBN $978-961-6254-56-4$

Kennedy, F., McDonnell, A., Gerrish, K., et al. (2012). Evaluation of the impact of nurse consultant roles in the United Kingdom: a mixed method systematic literature review. J Adv Nurs. 68, 721-742. doi:10.1111/j.1365-2648.2011.05811.x

Krzyzanowska, M.K., Kaplan, R., \& Sullivan, R. (2011). How may clinical research improve healthcare outcomes? Ann Oncol. Nov;22 Suppl 7:vii10-vii15. doi: 10.1093/annonc/mdr420. 
Logan, P.A., Gallimore, D., \& Jordan, S. (2015). Transition from clinician to academic: an interview study of the experiences of UK and Australian Registered Nurses. J Adv Nurs. 72(3), 593-604.

Morris, Z.S., Wooding, S., \& Grant, J. (2011). The answer is 17 years, what is the question: Understanding time lags in translational research. J Royal Soc Med. 104(12), 510-520.

NHS National Institute of Health Research (NIHR) (2016). Building a research career handbook. Retrieved from https://www.nihr.ac.uk/our-faculty/.../Building-a-research-careerhandbook.pdf.

Ozdemir, B.A., Karthikesalingam, A., Sinha, S., et al. (2015). Research activity and the association with mortality. PLoS One. Feb 26;10(2):e0118253. doi: 10.1371/journal.pone.0118253. eCollection 2015.

Pickstone, C., Nancarrow, S., Cooke, J., et al. (2008). Building research capacity in the allied health professions. Evid Policy. 4(1), 75-91.

Roddam, H., Cross, L., Georgiou, R., et al. (2019). Developing clinical academic researchers: insights from practitioners and managers in nursing, midwifery and allied health. Br J Health Care Manag. 25(9), 282-292.

Springett, K., Norton, C., Louth, et al. (2014). What are the tensions in research collaboration for NHS Trusts and HEIs? AUKUH NMAHPs Clinical Academic Careers Development Group, May 2014. Retrieved from http://www.aukuh.org.uk/index.php/affiliate-groups/nmahps/reports-andpublications.

Stephenson, J (2019). Analysis: More vacancies indicate nurse staffing is still in crisis. Nursing Times 06 September https://www.nursingtimes.net/news/workforce/analysis-vacancies-indicatenurse-staffing-still-crisis-06-09-2019/ 
Trusson D, Rowley E, Bramley L. (2019) A mixed-methods study of challenges and benefits of clinical academic careers for nurses, midwives and allied health professionals. BMJ Open 2019;9:e030595. doi: 10.1136/bmjopen-2019-030595

Van Oostveen, J., Goedhart, S., Francke, A., et al. (2017) Combining clinical practice and academic work in nursing: A qualitative study about perceived importance, facilitators and barriers regarding clinical academic careers for nurses in university hospitals. J Clin Nurs. 26(23-24), 4973-4984.

Westwood, G., Richardson, A., Latter, S., et al. (2018) Building clinical academic leadership capacity: sustainability through partnership. J Res Nurs. 23(4), 346-357.

Whitehouse, C. L., \& Smith, H. A. (2018). The Whitehouse report: Review of research nursing and midwifery structures, strategies and sharing of learning across the UK and Ireland in 2017. The Florence Nightingale Foundation.

Williamson G.R. (2004). Lecturer practitioners in UK nursing and midwifery: what is the evidence? A systematic review of the research literature. J Clin Nurs. 13, 787-795

Windsor, J., Searle, J., Hanney, R., et al. (2015) Building a sustainable clinical academic workforce to meet the future healthcare needs of Australia and New Zealand. Report from the first summit meeting. Intern Med J. 45, 965-971.

Windsor, J., Garrod, T., Talley, NJ., et al. (2017) The clinical academic workforce in Australia and New Zealand: report on the second binational summit to implement a sustainable training pathway. Intern. Med. J. 47(4), 394-399.

World Health Organization. (2016). Global strategic directions for strengthening nursing and midwifery 2016-2020. Geneva: WHO. 
387 Table 1: Clinical Academic Internship Programme - Taught Curriculum

\section{Research Methods Training Schedule}

\section{Training Day 1}

Designing a research question

Qualitative and quantitative research

Training Day 2

Literature searching and on-line databases

Critical appraisal

Roles and responsibilities

Training Day 3

Ethics in research

NHS ethical permissions and procedures

Academic institution ethics committees

Informed consent

Training Day 4

Good Clinical Practice (GCP) training

Training Day 5

Research proposal presentations, peer support, and formative feedback

Training Day 6

Introduction to statistics and relevant software

Training Day 7

Introduction to qualitative analysis and relevant software

Training Day 8

Principles of research dissemination

\section{Training Day 9}

Practical research skills workshops

Research funding

Research careers

Training Day 10

Research Showcase 
390 Table 2: Main questions from the Interview Guide

\section{Area of interest Question}

Background Information:

1 a) What was the main reason for you applying for the internship?

b) What were your experiences of completing the application form, and the shortlisting and interview process?

2 Please describe any encouragement (or otherwise) that you received from your manager(s) to apply?

3 How did your colleagues react to your successful appointment?

Course Content:

1 Which aspects of the training programme did you find most/least useful? Why?

2 In your experience of the overall programme so far what have been the worst aspects and please give any suggestions for improvements.

Individual Projects and Support:

1 How do you feel about the support you have received from University during the internship?

2 How do you feel about the support you have received from your NHS Trust during the internship?

Future Issues and Summary:

1 In what ways do you feel the programme and/or facilitation could be improved for future intakes?

2 How would you sum up your personal experience of undertaking the programme so far? 